\title{
Sliding-Mode Control for a Three-Phase Unity Power Factor Rectifier Operating at Fixed Switching Frequency
}

\author{
Ramon Guzman, Luis Garcia de Vicuña, Javier Morales, Miguel Castilla and Jose Matas
}

\begin{abstract}
This paper presents an improved variable hysteresisband current-control in natural frame for a three-phase unity power rectifier. The proposed control algorithm is based on three decoupled sliding-mode controllers combined with three independent Kalman filters. The use of Kalman filters instead of a non-adaptive state observer improves the quality of the estimated signals in presence of noise, increasing the immunity of the control loop in noisy environments. To reduce drastically the computational load in the Kalman algorithm, a reduced bilinear model is derived which allows to use a Kalman filter algorithm instead of an extended Kalman filter. A fast output-voltage control is also presented which avoids output-voltage variations when a sudden change in the load or a voltage sag appears. Moreover, a fixed switching frequency algorithm is proposed which uses a variable hysteresis-band in combination with a switching decision algorithm, ensuring a switching spectrum concentrated around the desired switching frequency. The overall control proposal has been fully integrated into a digital signal processor. Selected experimental results are introduced to validate the theoretical contributions of this paper.
\end{abstract}

Index Terms-Current control, LCL filter, Sliding Mode Control, Extended Kalman filter, Voltage sensorless.

\section{INTRODUCTION}

$\mathbf{T}$ HREE phase rectifiers are commonly used as an interface between the three-phase system and the ac-line in mostly electronic equipments which are supplied with a dc-voltage. Traditionally, ac to dc conversion is achieved using three-phase diode bridge rectifiers [1]. However these systems exhibits a low power factor (PF), and inject current harmonics to the grid. This drawback can cause non-desirable effects such as the increasing of the power supply voltage distortion, the damage of the rectifier due to overheating, and a noncorrect working of the equipment. Many solutions have been reported to improve the power factor and decrease the current harmonics in single-phase [2], [3], and three-phase rectifiers [4], [5]. An state-of-the art update about Unity Power Factor Rectifier (UPFR) can be found in [6], [7] and [8]. The UPFR are characterized by a high power factor, and a fast dynamic response can be achieved in the output voltage if a proper control algorithm is implemented.

Sliding mode control (SMC) is an appropriate way to control power converters due its inherent characteristics such as robustness, insensitivity to system parameter variation, and a fast dynamic response [9], [10]. However, a major drawback of this technique is the variable switching frequency, which is undesirable in many applications [11]-[13]. In the literature, some authors have investigated this problem being the digital hysteretic modulators the commonly given solution [14], [15]. However a high sampling frequency is needed for the correctly implementation of these digital hysteretic modulators to make the control algorithm effective. This problem can be solved if analog hysteretic comparators are used but at expenses of additional hardware [16]. Other solutions can be adopted by using predictive control and the DSP timers to decide the switching time [17].

Anyway, to achieve a current control with fixed switching frequency in natural frame, the three current controllers must be decoupled, that is each controller only depends on its own control variable [16], [18]. Therefore, a difficult on the implementation in natural frame appears, due to the crosscoupling through the neutral point voltage. Reference [19], [20] presents a solution to this problem in a voltage source inverter, with the disadvantage of the strong dependence with the filter inductor value. A different solution based on SMC is presented in [21] but only allows to decouple two of the three controllers.

Other commonly solutions are based on using transformations such as $\alpha \beta$-frame [22], [23], $d q$-frame [24] or using three independent current controllers which structure has to be changed over every $60^{\circ}$ [25], [26]. However, very little previous works have exploited the SMC technique for threephase systems in natural frame due to the cross-coupling problem.

An effective model-based solution using a Kalman filter is proposed in this paper to solve the axis-coupling problem. This technique is based on the estimation of the inductors currents. Besides, the estimated variables can be used also in the hysteresis current control (HCC) to reduce the switching noise and improving the switching frequency spectrum. It is well know that the Extended Kalman filter is the best solution in noisy environments but the principal drawback is the important computational load required for the algorithm. This paper tries to solve the problems previously mentioned and proposes a control algorithm for the UPFC with the following features: 1) the control system is based on SMC in natural frame, 2) a reduced bilinear model is derived which allows to use a Kalman filter (KF) instead of an extended Kalman filter (EKF) reducing drastically the computational load. Moreover a sensor-reduction can be achieved by eliminating the voltage sensors, increasing the system reliability, 3) the decoupling among controllers is based on the system model, 4) the variables used in the sliding surface are estimated and free of noise, improving the sliding-motion, 5) a digital implemen- 
tation of hysteretic modulators are designed to achieve fixed frequency, avoiding additional analog hardware in the system, 6) a robust feedforward current control is introduced, which provides a linear dynamics to the output voltage and robustness against load changes and voltage sags.

The main contributions of this paper are: 1) The controllers decoupling is based on the system model, allowing three independent current controllers with a fast dynamic response, 2) a feedforward current control which linearizes the output voltage and provides robustness against load changes and voltage sags, 3) a fixed switching frequency algorithm is proposed using a variable hysteresis-band in combination with a switching decision algorithm (SDA), ensuring a switching spectrum concentrated around the desired switching frequency. This control proposal is a fully digital implementation, programmed in a digital signal processor. The paper is organized as follows. In section II a non-linear model of the UPFR is presented. Section III introduces the problem formulation. In section IV the axis-decoupling approach based on an estimator is introduced. Section V presents the proposed control system, and the different blocks in the control algorithm will be explained in detail. Experimental results are reported in section VI. Finally, section VII concludes the paper.

\section{NON-Linear MOdel OF ThE UPFR}

A circuit scheme of an UPFR is depicted in Fig.1. An equivalent circuit for each phase-leg $i$, with $i \in\{a, b, c\}$, is shown in Fig.2. From this circuit, the three-phase system equations can be written as

$$
\begin{aligned}
L \frac{d \mathbf{i}}{d t} & =\mathbf{v}-\frac{v_{o}}{2} \mathbf{u}+v_{n} \mathbf{1} \\
C \frac{d v_{o}}{d t} & =i_{a} \frac{u_{a}}{2}+i_{b} \frac{u_{b}}{2}+i_{c} \frac{u_{c}}{2}-i_{o} \\
v_{n} & =\frac{v_{o}}{6}\left(u_{a}+u_{b}+u_{c}\right)
\end{aligned}
$$

where $v_{n}$ is the neutral point voltage, $\mathbf{i}=\left[\begin{array}{lll}i_{a} & i_{b} & i_{c}\end{array}\right]^{T}$ is the inductor current vector, $\mathbf{v}=\left[\begin{array}{lll}v_{a} & v_{b} & v_{c}\end{array}\right]^{T}$ is the grid voltage vector, $\mathbf{u}=\left[\begin{array}{lll}u_{a} & u_{b} & u_{c}\end{array}\right]^{T}$ is the control variables vector with $u_{a, b, c} \in\{ \pm 1\}, v_{o}$ is the output voltage and $\mathbf{1}^{T}$ is defined as $\left[\begin{array}{lll}1 & 1 & 1\end{array}\right]^{T}$.

The previous equations can be written in state-space form:

$$
\begin{aligned}
\frac{d \mathbf{x}}{d t} & =\mathbf{f}(\mathbf{x}, \mathbf{u})+\mathbf{E}\left(\mathbf{v}+v_{n}\right) \\
\mathbf{y} & =\mathbf{h}(\mathbf{x}, \mathbf{u})
\end{aligned}
$$

where

$$
\begin{gathered}
\mathbf{x}=\left[\begin{array}{llll}
i_{a} & i_{b} & i_{c} & v_{o}
\end{array}\right]^{T} \\
\mathbf{f}(\mathbf{x}, \mathbf{u})=\left(\begin{array}{cccc}
0 & 0 & 0 & -\frac{u_{a}}{2 L} \\
0 & 0 & 0 & -\frac{u_{b}}{2 L} \\
0 & 0 & 0 & -\frac{u_{c}}{2 L} \\
\frac{u_{a}}{2 C} & \frac{u_{b}}{2 C} & \frac{u_{c}}{2 C} & \frac{-1}{R_{L}}
\end{array}\right) \mathbf{x} \\
\mathbf{E}=\frac{1}{L}\left[\begin{array}{llll}
1 & 1 & 1 & 0
\end{array}\right]^{T}
\end{gathered}
$$

and the output matrix is given by $\mathbf{h}$

$$
\mathbf{H}=\frac{\partial \mathbf{h}}{\partial \mathbf{x}}=\left(\begin{array}{cccc}
1 & 0 & 0 & 0 \\
0 & 1 & 0 & 0 \\
0 & 0 & 1 & 0 \\
0 & 0 & 0 & 1
\end{array}\right)
$$

\section{Problem Formulation}

The main control objective in a UPRF is to guarantee sinusoidal input currents in phase with the grid voltages. A simple sliding surfaces for this purposes can be used

$$
\mathbf{S}=\mathbf{i}^{*}-\mathbf{i}
$$

where $\mathbf{i}^{*}=k \mathbf{v}=\left[\begin{array}{lll}i_{a}^{*} & i_{b}^{*} & i_{c}^{*}\end{array}\right]^{T}$, is the reference current vector. Using (1), (3) and (10) the dynamics for each sliding surface is represented by the following expressions:

$$
\begin{aligned}
\frac{d S_{a}}{d t} & =\frac{d i_{a}^{*}}{d t}-\frac{1}{L}\left(v_{a}-\frac{v_{o}}{2} u_{a}+\frac{v_{o}}{2} \frac{u_{a}+u_{b}+u_{c}}{3}\right) \\
\frac{d S_{b}}{d t} & =\frac{d i_{b}^{*}}{d t}-\frac{1}{L}\left(v_{b}-\frac{v_{o}}{2} u_{b}+\frac{v_{o}}{2} \frac{u_{a}+u_{b}+u_{c}}{3}\right) \\
\frac{d S_{c}}{d t} & =\frac{d i_{c}^{*}}{d t}-\frac{1}{L}\left(v_{c}-\frac{v_{o}}{2} u_{c}+\frac{v_{o}}{2} \frac{u_{a}+u_{b}+u_{c}}{3}\right) .
\end{aligned}
$$

The aforementioned expressions exhibit a cross-coupling term introduced by the neutral point voltage (3). This term can produce changes on the slopes of the sliding surfaces, depending on the discrete values of the control variables, $u_{a}, u_{b}$ and $u_{c}$. This phenomena is depicted in Fig.3 where it can seen that the slope of each sliding surface is affected by the three control variables. The procedure to achieve a decoupling among each phase-leg controller will be introduced in section IV.

The second objective is to achieve fixed switching frequency. Once the controllers are decoupled a variable hysteresis band can be used for this purpose. The problem of this method is the error in the desired switching frequency provoked by the samples which can appear out of the hysteresis bands. A switching decision algorithm will be introduced to solve this problem. The method will be explained in subsection $\mathrm{V}-\mathrm{C}$.

The third objective is to make the system robust against load changes and voltage sags. This will be achieved by an outputcurrent feedforward control which also linearize the outputvoltage dynamics.

The contributions of this paper are associated to each of the proposed solutions for the above mentioned control objectives.

\section{AXIS-DeCOUPLing BASED on AN Estimator}

In this section a linear simplified model is deduced to be used in the KF algorithm. This model is based on the axis-decoupling approach which purpose is to remove the dependence of the neutral point voltage from the control dynamics shown in (11)-(13). Besides this state space model is augmented in two additional states, $v_{i}$ and $v_{i q}$, in order to estimate the grid voltages by means a KF algorithm. 


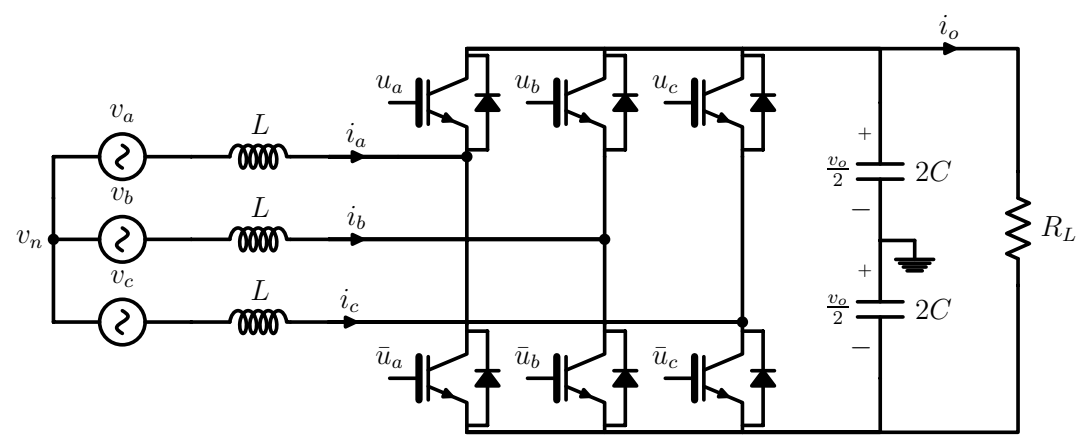

Fig. 1: Circuit diagram of three-phase unity power factor rectifier
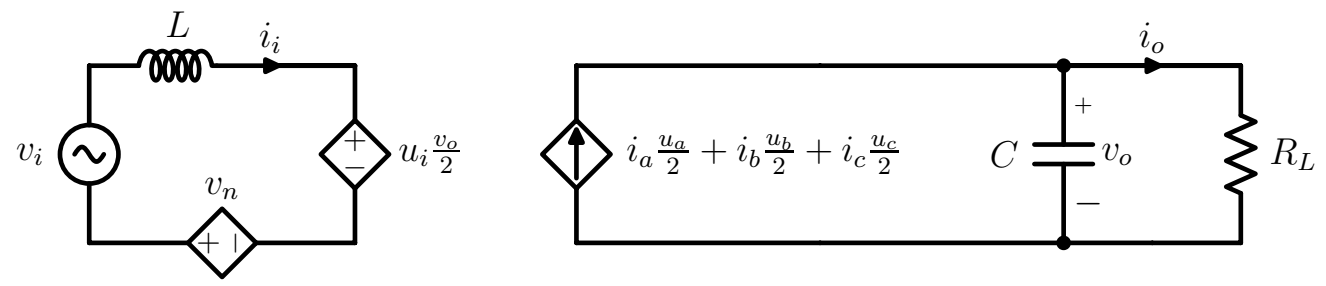

Fig. 2: Equivalent per-phase circuit of the unity power factor rectifier

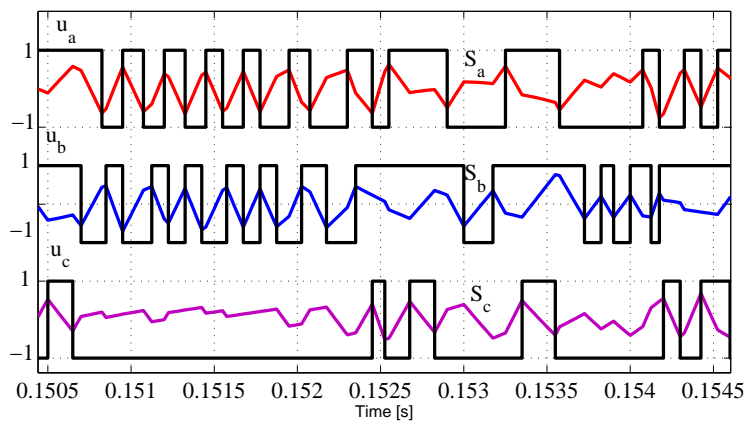

Fig. 3: Simulation result of cross-coupled sliding-mode controllers.

The first objective is to achieve three sliding surfaces $S_{a}$, $S_{b}$ and $S_{c}$ which only depends on its control variable $u_{a}, u_{b}$ and $u_{c}$ respectively, and which dynamics are

$$
\begin{aligned}
& \frac{d S_{a}}{d t}=\frac{d i_{a}^{*}}{d t}-\frac{1}{L}\left(v_{a}-\frac{v_{o}}{2} u_{a}\right) \\
& \frac{d S_{b}}{d t}=\frac{d i_{b}^{*}}{d t}-\frac{1}{L}\left(v_{b}-\frac{v_{o}}{2} u_{b}\right) \\
& \frac{d S_{c}}{d t}=\frac{d i_{c}^{*}}{d t}-\frac{1}{L}\left(v_{c}-\frac{v_{o}}{2} u_{c}\right) .
\end{aligned}
$$

Fig.4 shows the sliding surfaces and the control actions. As it can be seen the switching surfaces slopes are synchronized with their corresponding control variables. A linear simplified model used in a Kalman estimator will be used for this purpose.

In order to derive this model, some considerations must be taken into account. The first one is to ensure that the model is a decoupled model (i.e. each phase only depends on its own control variable) and second, the model must be linear, accurate, and simple to reduce the computational time. For these reasons the following assumptions are done:

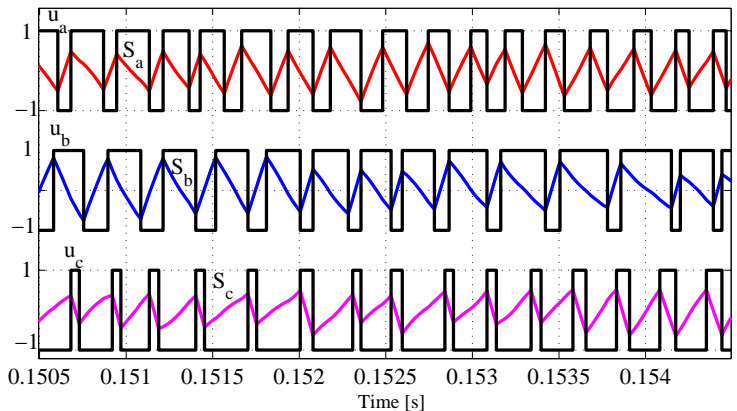

Fig. 4: Simulation result of decoupled sliding-mode controllers operating at fixed frequency.

1) a value of $v_{n}=0$ is taken in the converter model used in the KF, with this consideration the cross-coupling is removed.

2) the output capacitor is usually large and the output voltage has a slow dynamic. Hence, the state variable $v_{o}$ can be assumed constant between different sampling instants of the same switching period. Besides, since this variable is measured, it can be considered as a parameter and its dynamics can be neglected. With this consideration, the new space state model for each phase-leg $i$ could be considered linear in a switching period [27].

The second objective is to reduce the number of sensors. With this aim in mind, the state space model will be incremented with two additional states, $v_{i}$ and its quadrature $v_{i q}$, in order to estimate the grid voltages [28]. These voltages will be used in the sliding surfaces and in the hysteresis band expressions in subsection V-C.

With this considerations, the new differential equations for 
each phase-leg $i$ are:

$$
\begin{aligned}
\frac{d i_{i}}{d t} & =\frac{1}{L} v_{i}-\frac{v_{o}}{2 L} u_{i} \\
\frac{d v_{i}}{d t} & =\omega_{o} v_{i q} \\
\frac{d v_{i q}}{d t} & =-\omega_{o} v_{i}
\end{aligned}
$$

which can be represented by the following reduced bilinear state-space model:

$$
\begin{aligned}
\frac{d \mathbf{x}_{i}}{d t} & =\mathbf{A} \mathbf{x}_{i}+\mathbf{B} v_{o} u_{i} \\
y_{i} & =\mathbf{C} \mathbf{x}_{i}
\end{aligned}
$$

where

$$
\begin{gathered}
\mathbf{x}_{i}=\left[\begin{array}{lll}
i_{i} & v_{i} & v_{i q}
\end{array}\right]^{T} \\
\mathbf{A}=\left(\begin{array}{ccc}
0 & \frac{1}{L} & 0 \\
0 & 0 & \omega_{o} \\
0 & -\omega_{o} & 0
\end{array}\right) \\
\mathbf{B}=\left[\begin{array}{ccc}
-\frac{1}{2 L} & 0 & 0
\end{array}\right]^{T}
\end{gathered}
$$

The control algorithm does not use grid voltage sensors. Hence the value of the output matrix $\mathbf{C}$ can be defined as:

$$
\mathbf{C}=\left[\begin{array}{lll}
1 & 0 & 0
\end{array}\right]
$$

which yields to the following observability matrix

$$
\mathbf{O}=\left[\begin{array}{lll}
\mathbf{C} & \mathbf{C A} & \mathbf{C A}^{2}
\end{array}\right]^{T} .
$$

Moreover the controllability matrix $\Gamma$ is given by

$$
\boldsymbol{\Gamma}=\left[\begin{array}{lll}
\mathbf{B} & \mathbf{A B} & \mathbf{A}^{2} \mathbf{B}
\end{array}\right]
$$

Matrices $\mathbf{O}$ and $\boldsymbol{\Gamma}$ are both of full-rank, (i.e. $\operatorname{rank}\{\mathbf{O}\}=$ $\operatorname{rank}\{\boldsymbol{\Gamma}\}=3$ ), so that the system is controllable and can be observed using only the measured current $i_{i}$.

\section{Proposed Control System}

The control diagram for phase-leg $a$ is depicted in Fig.5 which consists on four blocks. The output voltage control computes the value of the gain $k$. This gain and the estimated variables obtained from the KF block are used to obtain the sliding mode surfaces. The SMC block uses a hysteresis band generator, and a SDA algorithm to improve the switching frequency spectrum. In next subsections these four control blocks will be explained in detail.

\section{A. Kalman Filter}

Since the system is clearly nonlinear an EKF should be used, with the drawback of the high computational time needed for the algorithm. This time can be drastically reduced if the model defined by (20)-(21) is used for each phase-leg. This model can be considered linear in a switching period, and a $\mathrm{KF}$ can be used instead of an EKF, leading to an important computational load reduction with similar results, as shown below.

The main features provided by the KF in this application can be sumarized as follows:

- The three controllers can be decoupled since the model defined by (20)-(21) is used.

- All the variables used in the control algorithm are estimated and free of noise. The Kalman estimators produce a filtered version of the inductor currents providing an improved sliding motion.

- The grid voltages can be estimated, so the number of measurement sensors is reduced.

For the digital KF implementation, the state space model (20) is discretized. The discrete model and measurement equations are given by the following expressions:

$$
\begin{aligned}
\mathbf{x}_{i_{k+1}} & =\mathbf{A}_{d} \mathbf{x}_{i_{k}}+\mathbf{B}_{d} v_{o_{k}} u_{i_{k}}+\eta_{i_{k}} \\
y_{i_{k}} & =\mathbf{C x}_{i_{k}}+\mathbf{w}_{i_{k}}
\end{aligned}
$$

where

$$
\begin{gathered}
\mathbf{A}_{d}=e^{A T_{s}} \cong \mathbf{I}+\mathbf{A} T_{s}=\left(\begin{array}{ccc}
1 & \frac{T_{s}}{L} & 0 \\
0 & 1 & \omega_{o} T_{s} \\
0 & -\omega_{o} T_{s} & 1
\end{array}\right) \\
\mathbf{B}_{d}=\int_{0}^{T_{s}} B e^{A \lambda} d \lambda \cong \mathbf{B} T_{s}=\left[\begin{array}{ccc}
-\frac{T_{s}}{2 L} & 0 & 0
\end{array}\right]^{T}
\end{gathered}
$$

being $\mathbf{I}$ the identity matrix and $T_{s}$ the sampling time. Here it is assumed that $v_{O_{k}}$ is a constant between samples of the same switching period, so that $v_{o_{k+1}} \cong v_{o_{k}}$, and the discrete model can be considered linear over the same switching period.

The process and the measurement noise vectors are $\eta_{k}$ and $\mathbf{w}_{k}$ respectively with covariance matrices are given by:

$$
\begin{aligned}
& \mathbf{Q}_{i_{k}}=E\left\{\eta_{i_{k}} \eta_{i_{k}}^{T}\right\} . \\
& \mathbf{R}_{i_{k}}=E\left\{\mathbf{w}_{i_{k}} \mathbf{w}_{i_{k}}^{T}\right\}
\end{aligned}
$$

The recursive Kalman algorithm computation is divided in two parts: 1) time updating and 2) measurement updating. The following equations show the recursive steps:

1) The time update step predicts the state ahead and the error covariance ahead using (35) and (36) respectively

$$
\begin{aligned}
\widehat{\mathbf{x}}_{i_{k}}^{-} & =\mathbf{A}_{d} \widehat{\mathbf{x}}_{i_{k-1}}^{-} \\
\mathbf{P}_{i_{k}}^{-} & =\mathbf{A}_{d} \mathbf{P}_{i_{k-1}} \mathbf{A}_{d}^{T}+\mathbf{Q}_{i_{k}}
\end{aligned}
$$

2) In the measurement update step an update for the predicted values are made using the Kalman gain which is computed using (37)

$$
\mathbf{L}_{i_{k}}=\mathbf{P}_{i_{k}}^{-} \mathbf{C}^{T}\left(\mathbf{C P}_{i_{k}}^{-} \mathbf{C}^{T}+\mathbf{R}_{i_{k}}\right)^{-1}
$$

This gain is calculated recursively in order to minimize the mean square error between the measured values and the predicted ones for the system states. When the gain is computed, the state estimation and the error covariance can be updated using (38) and (39) respectively

$$
\begin{aligned}
\widehat{\mathbf{x}}_{i_{k}} & =\widehat{\mathbf{x}}_{i_{k}}^{-}+\mathbf{L}_{k}\left(i_{i_{k}}-\widehat{i}_{i_{k}}^{-}\right) \\
\mathbf{P}_{i_{k}} & =\left(\mathbf{I}-\mathbf{L}_{i_{k}} \mathbf{C}\right) \mathbf{P}_{i_{k}}^{-} .
\end{aligned}
$$




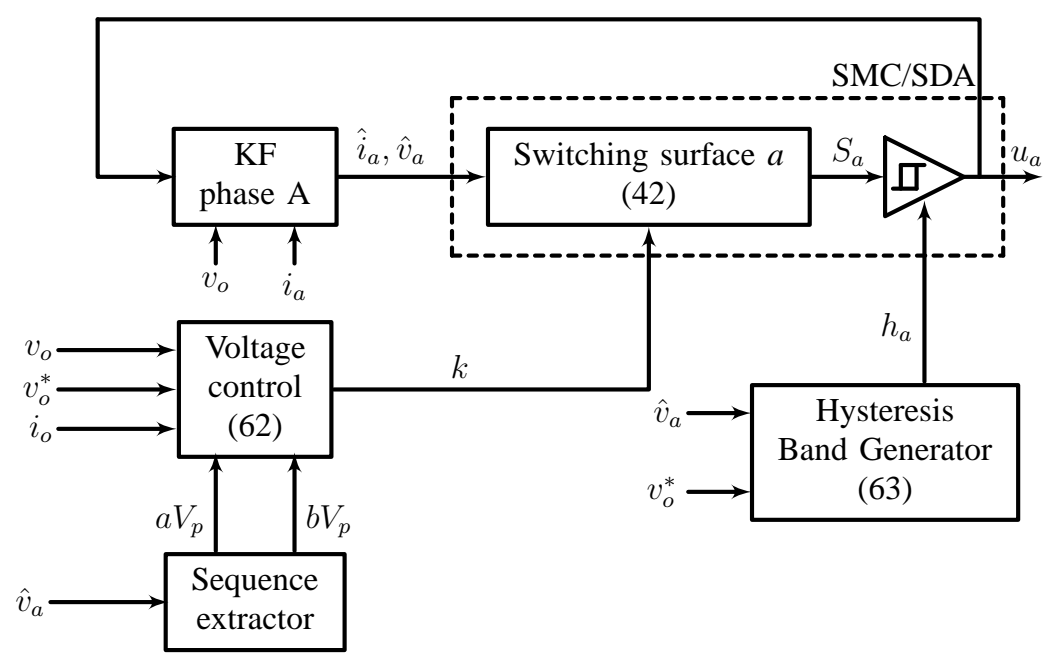

Fig. 5: Proposed control system for phase-leg $a$ of the UPFR

TABLE I:

SYSTEM PARAMETERS

\begin{tabular}{ccc}
\hline \hline Symbol & Description & Value \\
\hline$L$ & Filter input inductance & $5 \mathrm{mH}$ \\
$C$ & Output capacitor & $340 \mu \mathrm{F}$ \\
$V_{d c}$ & dc-link voltage & $250 \mathrm{~V}$ \\
$f_{s}$ & Sampling frequency & $40 \mathrm{kHz}$ \\
$f_{s w}$ & Switching frequency & $4 \mathrm{kHz}$ \\
$f_{g r i d}$ & Grid frequency & $60 \mathrm{~Hz}$ \\
$V_{g r i d}$ & Grid voltage & $50 \mathrm{Vrms}$ \\
$k_{p}$ & Proportional gain & 0.03 \\
$k_{i}$ & Integral gain & 2 \\
$R_{L}$ & Load & $135 \Omega$ \\
\hline
\end{tabular}

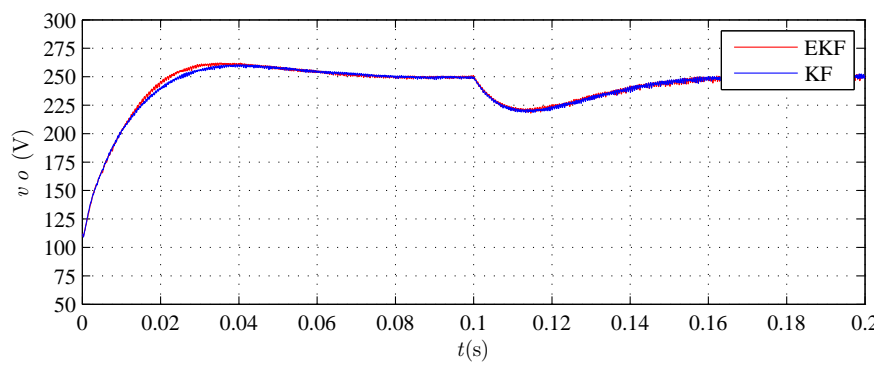

Fig. 6: Simulations results for the output voltage using an EKF and a KF with a load step change from 460 to $920 \mathrm{~W}$.

From (38) $\widehat{\mathbf{x}}_{i_{k}}=\left[\begin{array}{lll}\widehat{i}_{i} & \widehat{v}_{i} & \widehat{v}_{i q}\end{array}\right]$ is obtained.

In order to validate the proposed reduced bilinear model (20)-(21) used in KF versus the exact nonlinear model (4)-(5) with an EKF, the following simulations results are presented.

Fig.6 and Fig.7 show the simulation transient response of the output voltage and inductor currents to a load step change from 460 to $920 \mathrm{~W}$, using the system parameters listed in Table I. As it can be seen the output voltage and inductor current transient response are practically identical using either KF or EKF algorithms, which proves the validity of our proposal.

1) Practical Considerations: Election of $Q$ and $R$ matrices: For the correct implementation of the Kalman algorithm, matrices $\mathbf{R}_{i_{k}}$ and $\mathbf{Q}_{i_{k}}$ must be calculated. Matrix $\mathbf{R}_{i_{k}}$, which

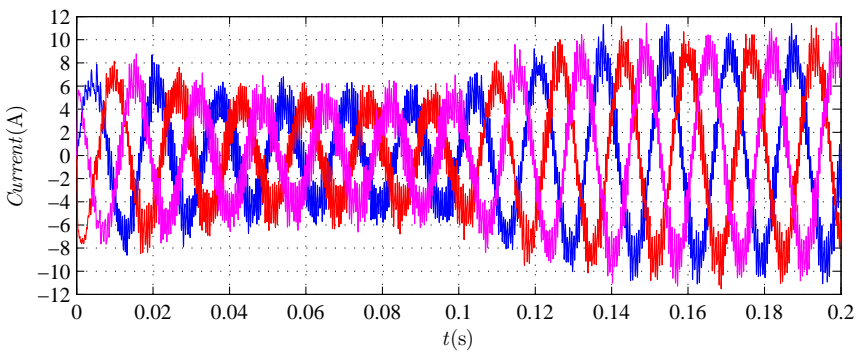

(a)

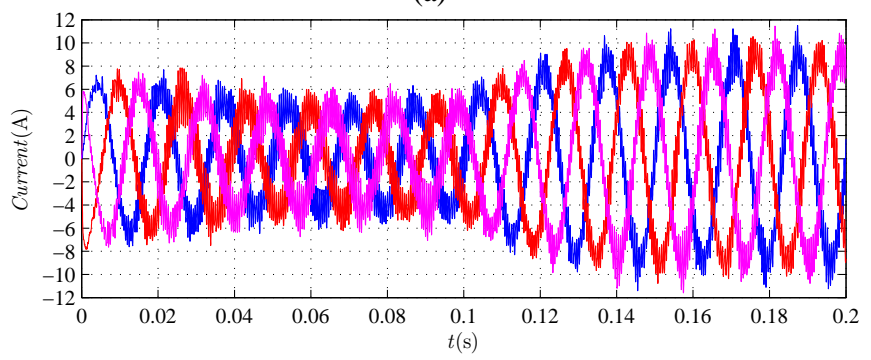

(b)

Fig. 7: Simulation results for inductor currents with a load step change from 460 to $920 \mathrm{~W}$ using (a) EKF and (b) KF.

dimension is equal to the dimension of the product $\mathbf{C P} \mathbf{P}_{i_{k}}^{-} \mathbf{C}^{T}$ can be estimated from measures. According to (26) and with the consideration that $\mathbf{P}_{i_{k}}^{-}$is a square matrix, $\mathbf{R}_{i_{k}}$ is reduced to an scalar. Hence, $R_{i_{k}}$ can be estimated using the unbiased mean power estimator

$$
R_{i_{k}}=\frac{1}{N T_{s}} \sum_{k=0}^{N-1}\left|w_{i_{k}}\right|^{2}
$$

where $w_{i_{k}}$ is an additive white gaussian noise sample at time $k$, in phase-leg $i$, and $N$ is the number of samples.

To obtain $w_{i_{k}}$, a reference dc-voltage used in the sensing system $V_{r e f_{k}}$, is employed. This voltage is connected at one analog input of the DSP and is contaminated with the system noise when the rectifier is switching. The noise samples can be obtained by subtracting from $V_{\text {ref }}$ measures, the exact 
value, $V_{\text {ref }}^{*}$ (i.e. the value when the rectifier is not switching), yielding

$$
R_{i_{k}}=\frac{1}{N T_{s}} \sum_{k=0}^{N-1}\left|V_{\text {ref }}-V_{\text {ref }}^{*}\right|^{2}
$$

The value obtained in this estimation was $R_{i_{k}} \cong 0.2$.

Matrix $\mathbf{Q}_{i_{k}}$ is more difficult to estimate and usually a tuning method is used. In this application $\mathbf{Q}_{i_{k}}$ is a diagonal matrix of dimension 3 and its value has been obtained by means of simulations. In the simulation results an approximate value of $\mathbf{Q}=0.005 \mathbf{I}_{3}$ has been obtained, where $\mathbf{I}_{3}$ is a 3-dimensional identity matrix. All the conditions in the Kalman algorithm are initialized to zero except for the covariance matrix which is initialized to the identity matrix.

2) Practical Considerations: Computational Load Reduction: A high computational load is usually a drawback in an EKF algorithm implementation. The first important reduction has been achieved when a KF with a reduced model have been used instead of the EKF with the nonlinear model. The possibility to reduce even more the time used in the computation will be an important improvement in the controller design. Specially, (37) contains a matrix inversion which needs an important computational load. Using the simplified model (24) instead of (7) only one measurement per phase can be used, and the matrix inversion of (37) is reduced to an scalar inversion. Moreover the noise $R_{i_{k}}$ can be considered so similar in each phases (i.e. $\mathbf{L}_{a_{k}} \cong \mathbf{L}_{b_{k}} \cong \mathbf{L}_{c_{k}}$ ), and the Kalman gain (37) is computed only for one phase. With these considerations the total time employed for the algorithm is around $4.9 \mu \mathrm{s}$ which makes the algorithm feasible.

\section{B. Sliding-Mode Control}

The conventional UPFR control scheme consist on a fastinner input-current loop which ensures sinusoidal input currents in phase with the line voltages, $\mathbf{i}=k \mathbf{v}$, and a slow-outer loop usually a PI controller, which main task is to regulate the output voltage, modifying the input-current amplitudes.

In this work a control design methodology is proposed to guarantee unity power factor and also provides a regulated output dc-voltage with fast dynamics response against sudden changes in the load. Besides, the amplitude control $k$ is conceived in order to linearize the output voltage dynamics.

1) Inner Control Loop: The current controllers can be derived using the following switching surfaces

$$
\begin{aligned}
S_{a} & =k \hat{v}_{a}-\hat{i}_{a} \\
S_{b} & =k \hat{v}_{b}-\hat{i}_{b} \\
S_{c} & =k \hat{v}_{c}-\hat{i}_{c}
\end{aligned}
$$

where $\hat{\mathbf{v}}=\left[\begin{array}{lll}\hat{v}_{a} & \hat{v}_{b} & \hat{v}_{c}\end{array}\right]$ and $\hat{\mathbf{i}}=\left[\begin{array}{lll}\hat{i}_{a} & \hat{i}_{b} & \hat{i}_{c}\end{array}\right]$ are the estimated grid voltages and inductor currents.

In the ideal case of sliding motion, that is, infinite switching frequency, the average value of $\mathbf{u}$ is known as equivalent control, $\mathbf{u}_{e q}$. The equivalent control is deduced by imposing the sliding regime condition $\dot{\mathbf{S}}=0$. Using (17) and (42)-(44), we can obtain:

$$
u_{e q i}=\frac{2}{v_{o}}\left(\widehat{v_{i}}-k L \frac{d \widehat{v_{i}}}{d t}-L \widehat{v_{i}} \frac{d k}{d t}\right)
$$

where $u_{e q i}$ is the equivalent control for each phase-leg $i$.

The main requirement in the design of SMC is to satisfy the reaching conditions, and also guarantee the existence of a sliding regime in the switching surfaces $\mathbf{S}=0$. The most often used reaching conditions for each phase-leg $i$ are given by

$$
S_{i} \dot{S}_{i}<0
$$

which allows us to determine the switching action

$$
u_{i}=\left\{\begin{array}{lll}
1 & \text { if } & S_{i}>0 \\
-1 & \text { if } & S_{i}<0
\end{array}\right.
$$

2) Outer Control Loop: In this work, the outer control loop is designed to exhibit a slow dynamics behavior to avoid input currents distortion, but with a fast dynamics response when a sudden change in the load appears. To achieve this, an appropriate control of the input current amplitude $k$ is proposed. This control has to two parts, the first one is a slow PI control which is the responsible to regulate the output voltage, and the second one is an output-current feedforward control which ensures a very fast response when a step change in the load is produced. The amplitude control $k$ is also conceived in order to linearize in a large signal sense the output voltage dynamics. Next, the control design procedure is described.

The zero dynamics concept [29] is used to design the outer loop. The zero dynamics analyzes the dynamics of $v_{o}$, assuming that the control objective $\mathbf{i}=k \mathbf{v}$ is achieved. The output-voltage differential equation in sliding regime can be found by using (45) in (2)

$$
\begin{aligned}
C \frac{d v_{o}}{d t} & =\frac{k}{v_{o}}\left(\hat{v}_{a}^{2}+\hat{v}_{b}^{2}+\hat{v}_{c}^{2}\right)-\frac{k L}{v_{o}} \frac{d k}{d t}\left(\hat{v}_{a}^{2}+\hat{v}_{b}^{2}+\hat{v}_{c}^{2}\right)- \\
& -\frac{k^{2} L}{v_{o}}\left(\hat{v}_{a} \frac{d \hat{v}_{a}}{d t}+\hat{v}_{b} \frac{d \hat{v}_{b}}{d t}+\hat{v}_{c} \frac{d \hat{v}_{c}}{d t}\right)-i_{o} .
\end{aligned}
$$

where the grid voltages have a sinusoidal waveform defined by:

$$
\begin{aligned}
& \hat{v}_{a}=V_{p} \cos \left(\omega_{o} t\right) \\
& \hat{v}_{b}=V_{p} \cos \left(\omega_{o} t-\frac{2 \pi}{3}\right) \\
& \hat{v}_{c}=V_{p} \cos \left(\omega_{o} t-\frac{4 \pi}{3}\right)
\end{aligned}
$$

being $V_{p}$ the grid-voltage peak-value. Using (49)-(51) in (48), the following equation is deduced:

$$
C \frac{d v_{o}}{d t}=\frac{3 V_{p}^{2} k}{2 v_{o}}\left(1-L \frac{d k}{d t}\right)-i_{o}
$$

As shown in [30], [31] the term $d k / d t$ can be neglected since the energy stored in the inductor is smaller than the energy stored in the capacitor. For a detailed demonstration, please see [30]. As a consequence 52 can be approximated by:

$$
C \frac{d v_{o}}{d t} \simeq \frac{3 V_{p}^{2} k}{2 v_{o}}-i_{o}
$$

The output-voltage differential equation (53) is clearly nonlinear, and the output-voltage dynamics depends on a proper 
design of $k$. In order to linearize the output voltage dynamics, the following nonlinear control of $k$ is proposed:

$$
k=\frac{2 v_{o}}{3 V_{p}^{2}}\left[k_{i} \int_{-\infty}^{t}\left(v_{o}^{*}-v_{o}\right) d \tau+k_{p}\left(v_{o}^{*}-v_{o}\right)+k_{0} i_{o}\right]
$$

where $k_{p}$ and $k_{i}$ are the proportional and integral gains respectively and $k_{0}$ can take the values 0 or 1 . Now, by replacing (54) in (53) yields

$$
C \frac{d v_{o}}{d t}=\left[k_{i} \int_{-\infty}^{t}\left(v_{o}^{*}-v_{o}\right) d \tau+k_{p}\left(v_{o}^{*}-v_{o}\right)-\left(1-k_{0}\right) i_{o}\right] .
$$

The dynamics of $v_{o}$ can be obtained by taking the time derivative of (55), which in the case of resistive load takes the following form:

$$
C \frac{d^{2} v_{o}}{d t^{2}}+\left(k_{p}+\frac{\left(1-k_{0}\right)}{R_{L}}\right) \frac{d v_{o}}{d t}+k_{i} v_{o}=k_{i} v_{o}^{*} .
$$

The last equation is a linear differential equation, which dependence on the load value can be removed by taking the value $k_{0}=1$. In this case a current feedforward term is introduced and the system will be robust against sudden load variations. In the other case, if only a PI controller is used (i.e. $k_{0}=0$ ) the output voltage dynamics will be affected by the output current variations producing an output voltage drop, (see Fig.6). The stability can be assured if $k_{p}$ and $k_{i}$ are chosen as positive values. It must be noted that, to obtain this controller unlike others controllers presented in the literature [32], [33], the use of small-signal models are not required.

\section{Output Voltage dynamics under Asymmetrical Fault}

The estimated grid voltage can be separated into positive and negative sequence components. The positive and negative sequence voltages as a function of time can be represented as:

$$
\begin{aligned}
& \hat{v}_{a}=a V_{p} \cos \left(\omega_{o} t\right)+b V_{p} \cos \left(\omega_{o} t+\phi\right) \\
& \hat{v}_{b}=a V_{p} \cos \left(\omega_{o} t-\frac{2 \pi}{3}\right)+b V_{p} \cos \left(\omega_{o} t+\frac{2 \pi}{3}+\phi\right) \\
& \hat{v}_{c}=a V_{p} \cos \left(\omega_{o} t-\frac{4 \pi}{3}\right)+b V_{p} \cos \left(\omega_{o} t+\frac{4 \pi}{3}+\phi\right)
\end{aligned}
$$

where $\phi$ is the phase angle of the negative sequence relative to the positive sequence and the parameters $a$ and $b$ specify the degree of imbalance. For example, a balanced three-phase voltage is an special case of (57)-(59), where $a=1$ and $b=0$.

Using (57)-(59) and (48), the following expression for the output voltage dynamics, in presence of a voltage sag, can be found:

$$
\begin{aligned}
C \frac{d v_{o}}{d t} & =\frac{3 k}{2 v_{o}}\left(\left(a V_{p}\right)^{2}+\left(b V_{p}\right)^{2}+2\left(a V_{p}\right)\left(b V_{p}\right) \cos \left(2 \omega_{o} t+\phi\right)\right) \\
& +\frac{3 K^{2} L \omega_{o}}{v_{o}}\left(a V_{p}\right)\left(b V_{p}\right) \operatorname{sen}\left(2 \omega_{o} t+\phi\right)-i_{o} .
\end{aligned}
$$

The previous expression shows that a ripple frequency component of $2 \omega_{o}$ appears in the output voltage when an asymmetrical fault occurs. The first step to obtain an appropriate voltage control robust against voltage sags, is to derive an averaged

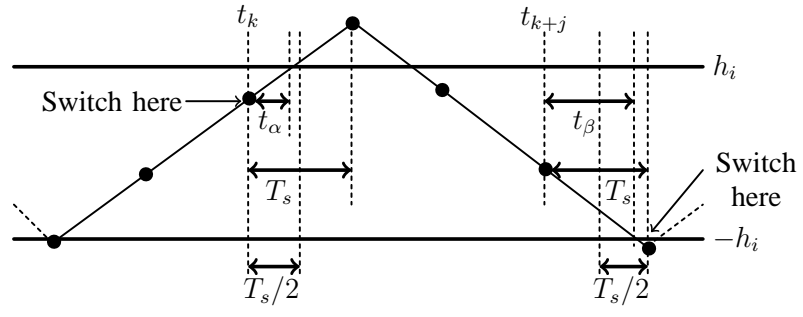

Fig. 8: Hysteresis band with the switching surface.

dynamic model. By averaging (60) in a half grid period the following expression can be deduced:

$$
C \frac{d\left\langle v_{o}\right\rangle}{d t}=\frac{3 k}{2\left\langle v_{o}\right\rangle}\left(\left(a V_{p}\right)^{2}+\left(b V_{p}\right)^{2}\right)-\left\langle i_{o}\right\rangle
$$

where the symbol \langle\rangle means average value. It is worth to mention that the above expression coincides with (53) with $a=1$ and $b=0$, (i.e. in absence of voltage sag). With the aim of linearize the output voltage dynamics when a voltage sag appears, the control $k(54)$ is modified as follows:

$$
\begin{aligned}
k & =\frac{2 v_{o}}{3\left(\left(a V_{p}\right)^{2}+\left(b V_{p}\right)^{2}\right)}\left[k_{i} \int_{-\infty}^{t}\left(v_{o}^{*}-v_{o}\right) d \tau+\right. \\
& \left.+k_{p}\left(v_{o}^{*}-v_{o}\right)+k_{0} i_{o}\right]
\end{aligned}
$$

The positive and negative sequence amplitude can be obtained using a sequence detector [34], [35].

\section{Hysteresis Band Generator with SDA}

It is well known that the SMC is characterized by a variable switching frequency which is usually not desired in most industry applications. The aim of this section is to design a fully digital hysteresis modulator that fixes the switching frequency modifying the hysteresis band. In analog hysteretic control, the expression of the hysteresis band is given by [16]

$$
h_{i}=\frac{v_{o}}{8 L f_{s w}}\left[1-\left(\frac{2 \hat{v}_{i}}{v_{o}}\right)^{2}\right]
$$

where $f_{s w}$ is the switching frequency.

While the sliding surface is moving inside the hysteresis bands $\pm h_{i}$, the switching frequency $f_{s w}$ will remain constant. If a digital control is used, an error in the switching frequency is produced due to the sampling process. Fig. 8 shows this phenomena, where some samples can be out of the hysteresis tbands and the switching frequency obtained will be lower than the desired one. To eliminate this error and concentrate the switching frequency spectrum around the desired frequency, a switching decision algorithm has been implemented.

Assuming the hysteresis band has a slow variation in a sampling period, $h_{i}\left(t_{k}\right) \simeq h_{i}\left(t_{k+1}\right)$, the algorithm can be implemented with the following steps:

1) When a sample is acquired, the time between the sample and the hysteresis band is calculated as follows: 


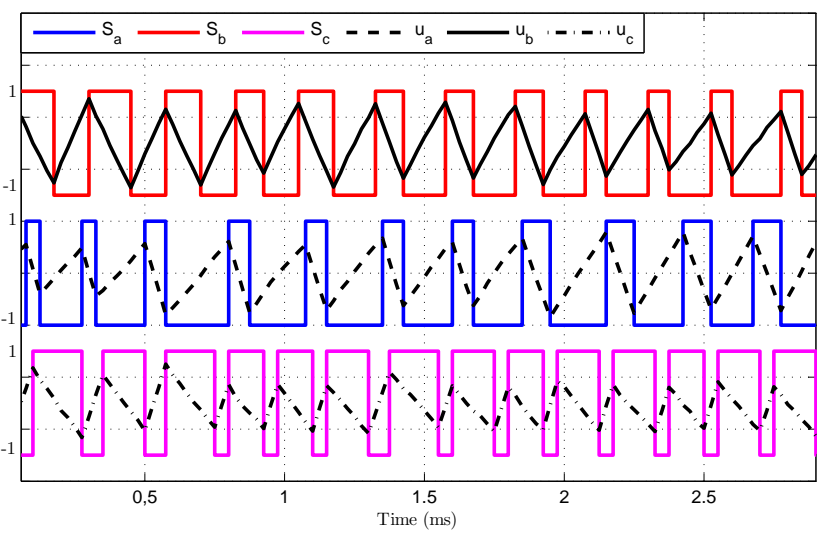

Fig. 9: Experimental control signals $u_{a}, u_{b}$ and $u_{c}$ with sliding surfaces $S_{a}, S_{b}$ and $S_{c}$

If the sample is in the increasing slope of the switching surface, $m_{1}$, where:

$$
m_{1}=\frac{1}{L}\left(\hat{v}_{i}+\frac{v_{o}}{2}\right)
$$

the time $t_{\alpha}$ can be computed as:

$$
t_{\alpha}=m_{1}\left[h_{i}-S_{i}\left(t_{k}\right)\right]
$$

otherwise, if the sample is in the decreasing slope of the switching surface, $m_{2}$, where:

$$
m_{2}=-\frac{1}{L}\left(\frac{v_{o}}{2}-\hat{v}_{i}\right)
$$

the time $t_{\beta}$ can be computed as:

$$
t_{\beta}=-m_{2}\left[S_{i}\left(t_{k+j}\right)+h_{i}\right]
$$

being $S_{i}$ is the switching surface for the phase-leg $i$.

2) When the estimated times, $t_{\alpha}$ and $t_{\beta}$ are known, the SDA is as follows:

In the case of increasing slope:

- If $t_{\alpha}<\frac{T_{s}}{2}$, the switching is done, otherwise a new sample is taken.

In the case of decreasing slope:

- If $t_{\beta}<\frac{T_{s}}{2}$, the switching is done, otherwise a new sample is taken.

This procedure is done recursively for each sampling period.

\section{EXPERIMENTAL RESUlTS}

An experimental three-phase rectifier prototype was built using a 4.5-kVA SEMIKRON full-bridge as the power converter and a TMS320F28M36 floating-poin digital signal processor (DSP) as the control platform with a sampling frequency of 40 $\mathrm{kHz}$. The grid voltages have been generated using a PACIFIC 360-AMX source. The system parameters are listed in Table I. The proposed control scheme was shown in Fig.5.

Fig.9 shows the control signals $u_{a}, u_{b}$ and $u_{c}$ and their corresponding switching surfaces, $S_{a}, S_{b}$ and $S_{c}$ in the case of decoupled controllers. As it can be seen the result obtained

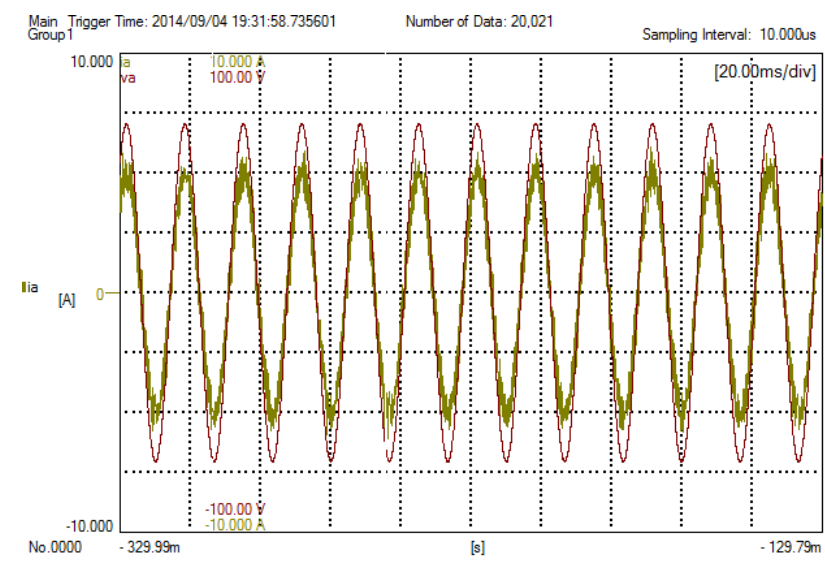

Fig. 10: Experimental inductor-current $(5 \mathrm{~A} / \mathrm{div})$ and gridvoltage (20V/div) for phase-leg $a$.

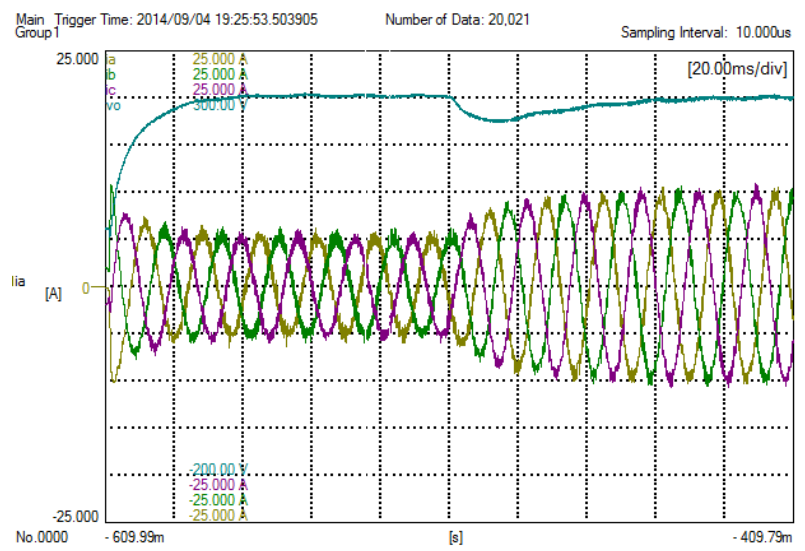

(a)

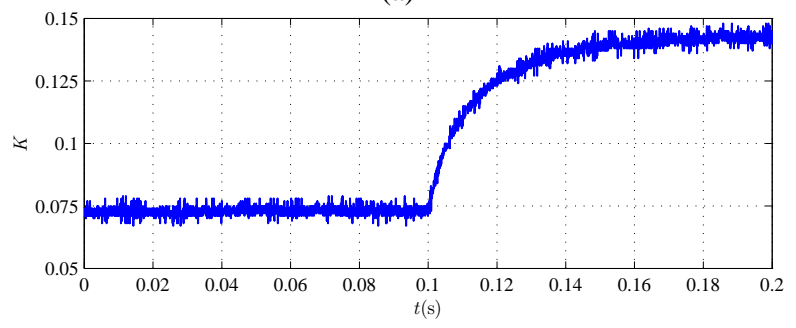

(b)

Fig. 11: (a) Experimental results for output voltage (50V/div) and three inductor currents $(5 \mathrm{~A} / \mathrm{div})$ without feedforward term with a load step change from 460 to $920 \mathrm{~W}$, (b) $k$ value.

is similar to the simulated one in Fig.4. Therefore we can conclude that the proposed control provides a perfect axisdecoupling with a fixed switching frequency, as expected.

Fig.10 shows the inductor current from phase-leg $a$ and the grid voltage $v_{a}$. The two signals are in phase providing a unity $\mathrm{PF}$, as desired.

With the aim to analyze the effect of the feedforward term in the output voltage control two cases are presented.

1) In Fig.11 the output voltage, the inductor-currents and $k$ are depicted, without using the feedforward term $\left(k_{0}=0\right)$. Fig.11(a) shows the dynamics of the output voltage (56) and the three-phase inductor currents. An important voltage drop appears in the output voltage, when a sudden load change 


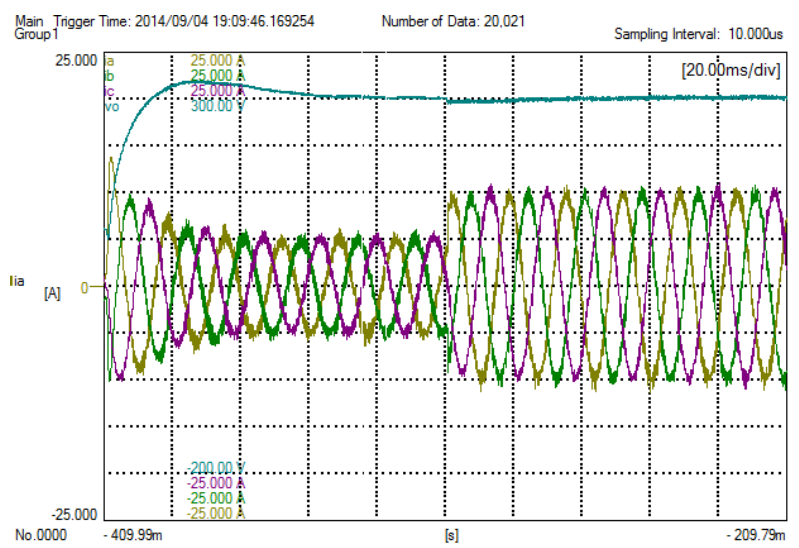

(a)

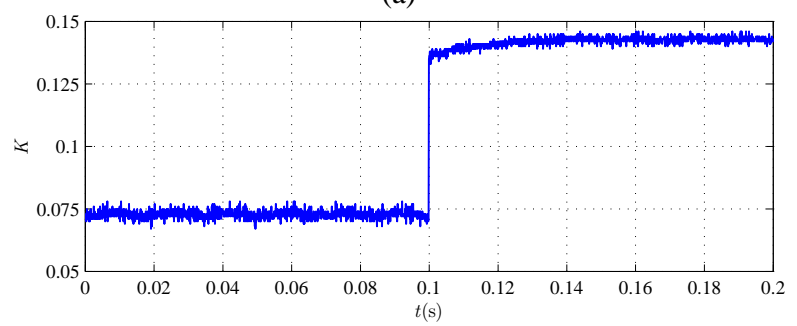

(b)

Fig. 12: (a) Experimental results for output voltage and three inductor currents with feedforward term with a load step change from 460 to $920 \mathrm{~W}$, (b) $k$ value.

from $460 \mathrm{~W}$ to $920 \mathrm{~W}$ is produced. Fig.11(b) shows the $k$ parameter. As it can be deduced from the figure, the settling time is around $0.08 \mathrm{~s}$ due the slow dynamics of the conventional PI controller.

2) The same waveforms are shown in Fig.12 but using the feedforward term $\left(k_{0}=1\right)$. The dynamics of $v_{o}$ is now independent of the load change as it is shown Fig.12(a). In this case the settling time of the $k$ parameter is drastically reduced, being the voltage drop inappreciable.

Fig.13(a) shows the output voltage and the grid voltages during an asymmetrical grid fault. The control amplitude $k$ is calculated by (54) and in this case a voltage drop appears in the output voltage, similar as in Fig.11(a). Note that a ripple frequency component of $2 \omega_{o}$ appears in the output voltage as expected .

In Fig.13(b) the output voltage and the three-phase currents are shown. As it can be seen the currents tracks the grid asymmetrical voltages during the sag.

The same waveforms are shown in Fig.14 but in this case using the control amplitude $k$ expressed in (62). Fig.14(a) and 14(b) show that the voltage drop is insignificant. As expected the ripple of $2 \omega_{o}$ is maintained.

The hysteresis band with its switching surface of phase-leg $a$ are shown in Fig.15. If an hysteresis band without the SDA algorithm is used, an error on the desired switching frequency appears. In Fig.15(a) this problem can be clearly seen, where several samples are out of the hysteresis limits provoking an error in the desired switching frequency. The problem is solved using the SDA algorithm presented in section IV-C. Fig.15(b) shows how the number of samples that are out of bounds of

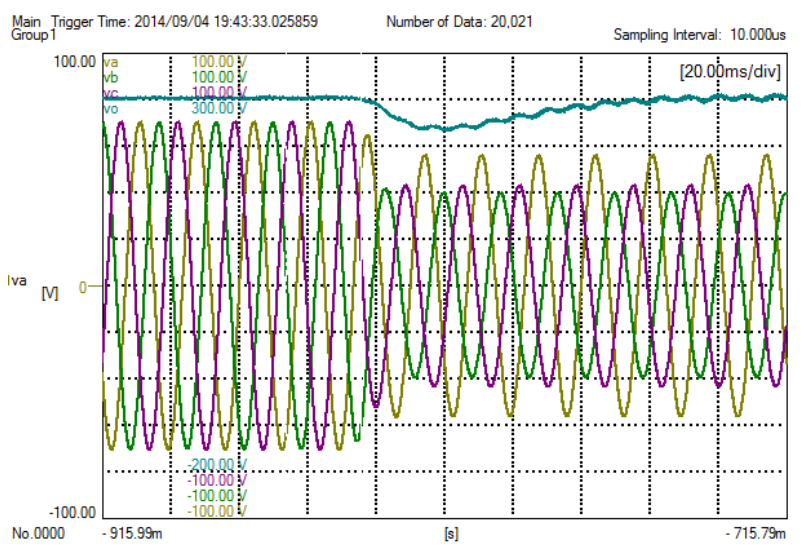

(a)

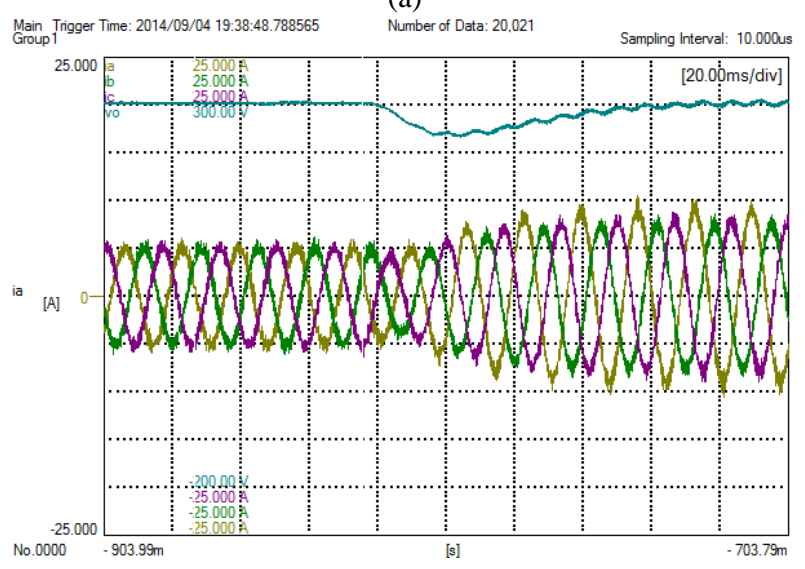

(b)

Fig. 13: (a) Output voltage (50V/div) and three phase voltage waveforms (20V/div) with asymmetrical fault $(a=0.65, b=0.15)$ using (54). (b) Output voltage and three phase currents waveforms $(5 \mathrm{~A} / \mathrm{div})$.

the hysteresis limits have been reduced using this algorithm, and the error is solved as it will be seen in the next results.

Finally, the spectrum of the switching frequency is shown in the following figures. In Fig.16(a), the spectrum of the control signal is depicted without the use of estimated currents. In this case the switching frequency is concentrated between $8 \mathrm{kHz}$ and 10kHz. Fig.16(b) shows the spectrum using estimated currents but without the hysteresis modulator. As it can be seen the switching frequency is incremented, starting at $11 \mathrm{kHz}$ to $20 \mathrm{kHz}$. The use of the KF increments the switching speed but with a spread spectrum. Fig.16 (c) shows the switching spectrum with hysteresis bands but without the SDA algorithm. The spectrum is concentrated around a fixed switching frequency of $3 \mathrm{kHz}$ but with an error, since the desired switching frequency is $4 \mathrm{kHz}$. This problem is overcome using the SDA algorithm, and the result is depicted on Fig.16(d), where the switching frequency is now around $4 \mathrm{kHz}$.

\section{CONCLUSIONS}

In this paper a hysteresis current control algorithm for a three-phase UPFR have been designed and tested. The control algorithm uses a SMC in combination with a KF to control the input currents achieving a high PF. The reference current 


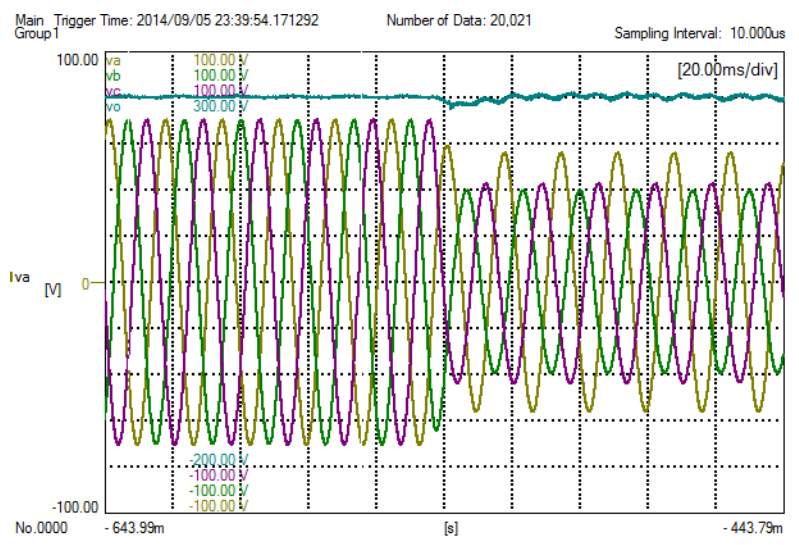

(a)

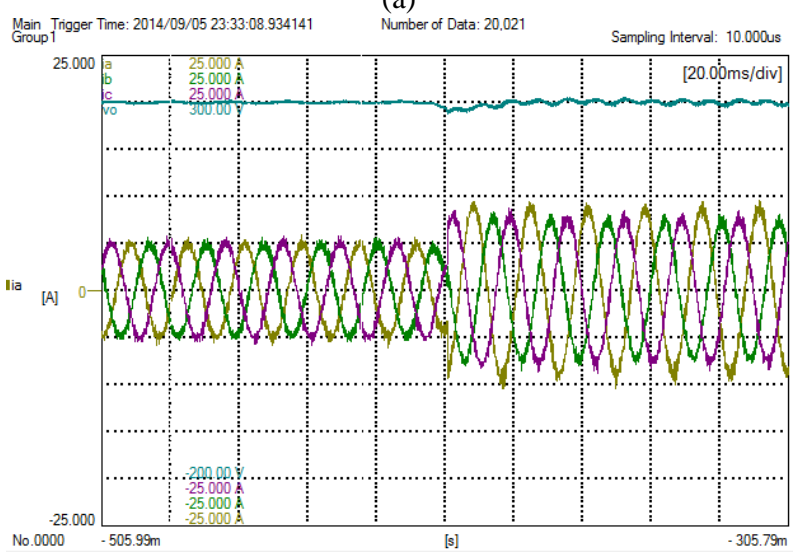

(b)

Fig. 14: (a) Output voltage (50V/div) and three phase voltage waveforms (20V/div) with asymmetrical fault ( $a=0.65, b=0.15)$ using (62). (b) Output voltage and three phase currents waveforms $(5 \mathrm{~A} / \mathrm{div})$.

is generated by means of a voltage control, which provides an adaptive value of $k$ that apart of calculate the correct amplitude of the reference current, provides a linear dynamics to the output voltage with a fast dynamics response. The hysteretic modulator obtains the adequate hysteresis band which in combination with an SDA algorithm concentres the spectrum of the SMC around a desired switching frequency improving the switching spectrum. The features of the proposed control are validated experimentally.

\section{ACKNOWLEDGEMENTS}

This work was partially supported by the Ministerio de Economia y Competitividad of Spain and FEDER founds under Project ENE2012-37667-C02-02 and by the CYTED programme under grant 713RT0475

\section{REFERENCES}

[1] A. Prasad, P. Ziogas, and S. Manias, "An active power factor correction technique for three-phase diode rectifiers," IEEE Trans. Power Electron., vol. 6, no. 1, pp. 83-92, Jan 1991.

[2] Y.-W. Cho, J.-M. Kwon, and B.-H. Kwon, "Single power-conversion acdc converter with high power factor and high efficiency," IEEE Trans. Power Electron., vol. 29, no. 9, pp. 4797-4806, Sept 2014.

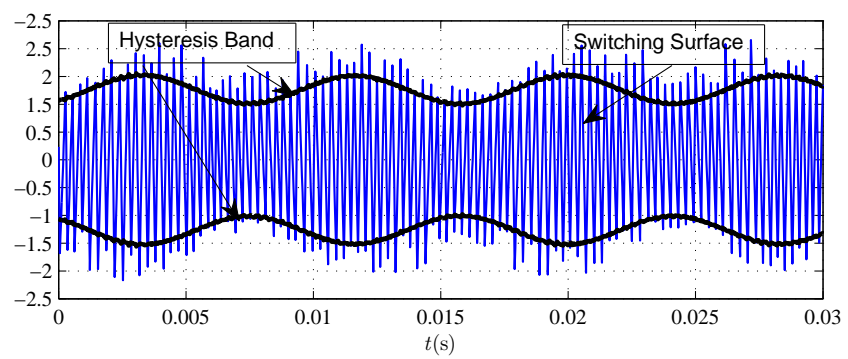

(a)

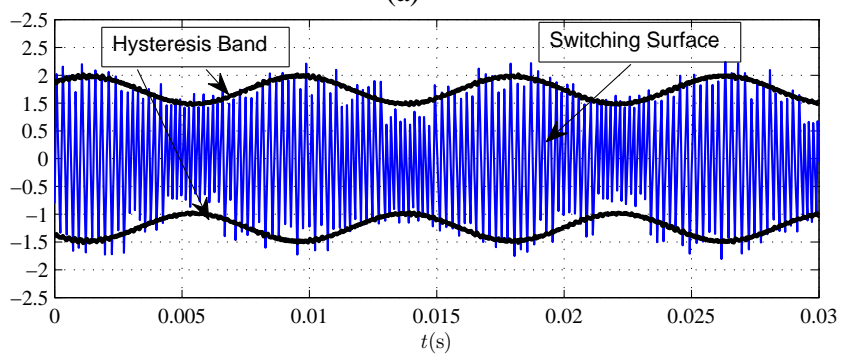

(b)

Fig. 15: Experimental switching surface and its hysteresis band for phase-leg $a$ (a) without SDA (b) with SDA.

[3] B. Mather and D. Maksimovic, "A simple digital power-factor correction rectifier controller," IEEE Trans. Power Electron., vol. 26, no. 1, pp. 919, Jan 2011.

[4] E. Mehl and I. Barbi, "An improved high-power factor and low-cost three-phase rectifier," IEEE Trans. Ind. Appl., vol. 33, no. 2, pp. 485492, Mar 1997.

[5] A. Maswood, A. Yusop, and M. Azizur Rahman, "A novel suppressedlink rectifier-inverter topology with near unity power factor," IEEE Trans. Power Electron., vol. 17, no. 5, pp. 692-700, Sep 2002.

[6] J. Kolar and T. Friedli, "The essence of three-phase pfc rectifier systemspart i," IEEE Trans. Power Electron., vol. 28, no. 1, pp. 176-198, Jan 2013.

[7] T. Friedli, M. Hartmann, and J. Kolar, "The essence of three-phase pfc rectifier systems-part ii," IEEE Trans. Power Electron., vol. 29, no. 2, pp. 543-560, Feb 2014.

[8] H. Kanaan and K. Al-Haddad, "Three-phase current-injection rectifiers: Competitive topologies for power factor correction," IEEE Magazine Ind. Electron., vol. 6, no. 3, pp. 24-40, Sept 2012.

[9] Z. Chen, "Pi and sliding mode control of a cuk converter," IEEE Trans. Power Electron., vol. 27, no. 8, pp. 3695-3703, Aug 2012.

[10] X. Hao, X. Yang, T. Liu, L. Huang, and W. Chen, "A sliding-mode controller with multiresonant sliding surface for single-phase gridconnected vsi with an lcl filter," IEEE Trans. Power Electron., vol. 28, no. 5, pp. 2259-2268, May 2013.

[11] F. Liu and A. Maswood, "A novel variable hysteresis band current control of three-phase three-level unity PF rectifier with constant switching frequency," IEEE Trans. Power Electron., vol. 21, no. 6, pp. 1727-1734, Nov 2006.

[12] L. Hoon, V. Utkin, and A. Malinin, "Chattering reduction using multiphase sliding mode control,” vol. 82, no. 9, pp. 1720-1737, Sep 2009.

[13] A. Abrishamifar, A. Ahmad, and M. Mohamadian, "Fixed switching frequency sliding mode control for single-phase unipolar inverters," IEEE Trans. Power Electron., vol. 27, no. 5, pp. 2507-2514, May 2012.

[14] A. Maswood and F. Liu, "A unity power factor front-end rectifier with hysteresis current control," IEEE Trans. Energy Conv., vol. 21, no. 1, pp. 69-76, March 2006 .

[15] A. Maswood, E. Al-Ammar, and F. Liu, "Average and hysteresis currentcontrolled three-phase three-level unity power factor rectifier operation and performance," IET Power Electron., vol. 4, no. 7, pp. 752-758, Aug 2011.

[16] D. Holmes, R. Davoodnezhad, and B. McGrath, "An improved threephase variable-band hysteresis current regulator," IEEE Trans. Power Electron., vol. 28, no. 1, pp. 441-450, Jan 2013.

[17] W. Stefanutti and P. Mattavelli, "Fully digital hysteresis modulation with 


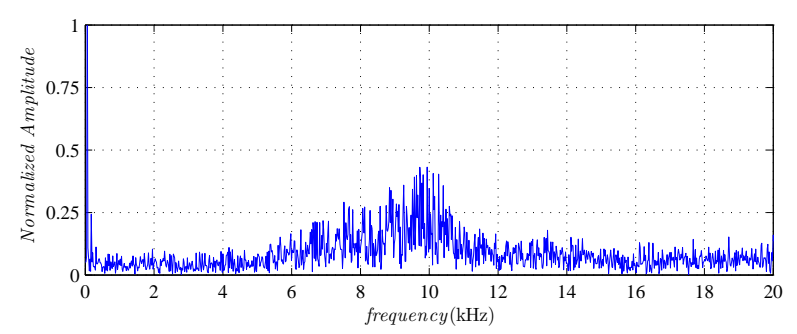

(a)

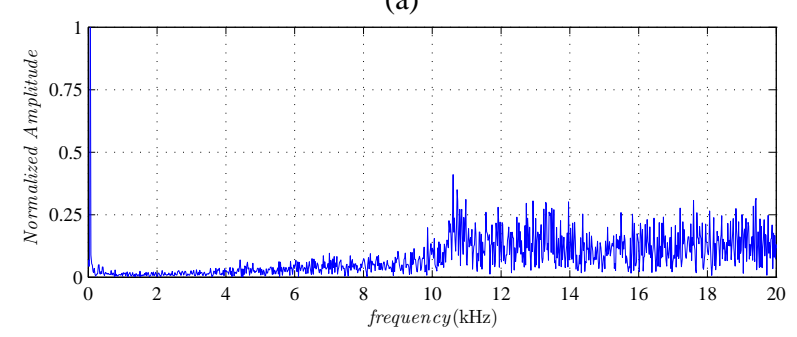

(b)

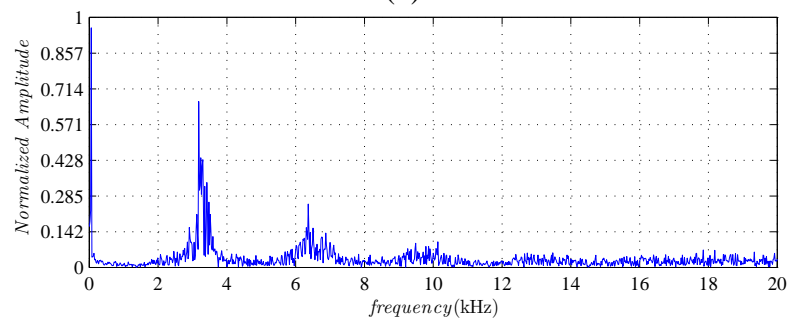

(c)

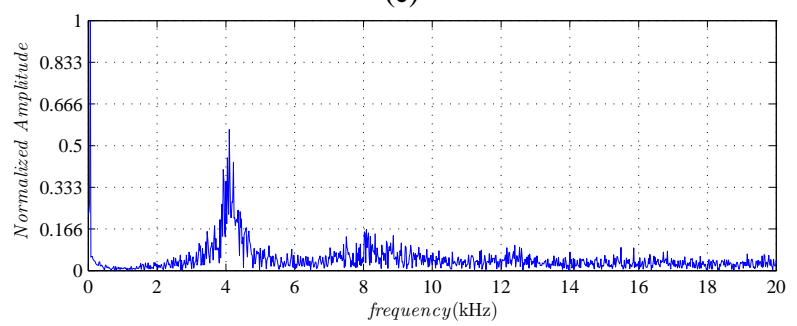

(d)

Fig. 16: Experimental switching frequency spectrum with amplitude relative to fundamental (a) without estimated signals (b) with estimated signals but without hysteresis modulator, (c) with estimated signals and hysteresis modulator and (d) with estimated signals, hysteresis modulator and SDA algorithm.

switching-time prediction," IEEE Trans. Ind. Appl., vol. 42, no. 3, pp. 763-769, May 2006.

[18] L. Malesani, P. Mattavelli, and P. Tomasin, "Improved constantfrequency hysteresis current control of vsi inverters with simple feedforward bandwidth prediction," IEEE Trans. Ind. Applications., vol. 33, no. 5, pp. 1194-1202, Sep 1997.

[19] W. Yan, J. Hu, V. Utkin, and L. Xu, "Sliding mode pulsewidth modulation," IEEE Trans. Power Electron.,, vol. 23, no. 2, pp. 619-626, 2008.

[20] Y. Alsmadi, V. Utkin, and L. Xu, "Sliding mode control of ac/dc power converters," in Power Engineering, Energy and Electrical Drives (POWERENG), 2013 Fourth International Conference on, May 2013, pp. $1229-1234$.

[21] R. Guzman, L. Garcia de Vicuna, A. Camacho, J. Matas, M. Castilla, and J. Miret, "Active damping control for a three phase grid-connected inverter using sliding mode control," in Ind. Electron. Society, IECON 2013 - 39th Annual Conference of the IEEE, Nov 2013, pp. 382-387.

[22] B. Wang, G. Venkataramanan, and A. Bendre, "Unity power factor control for three-phase three-level rectifiers without current sensors,"
IEEE Trans. Ind. Appl., vol. 43, no. 5, pp. 1341-1348, Sept 2007.

[23] J. Korelic and K. Jezernik, "Predictive variable-structure system control of unity power factor rectifiers," IET Power Electron., vol. 6, no. 8, pp. 1608-1617, September 2013.

[24] B. Bahrani, A. Karimi, B. Rey, and A. Rufer, "Decoupled dq-current control of grid-tied voltage source converters using nonparametric models," IEEE Trans. Ind. Electron., vol. 60, no. 4, pp. 1356-1366, April 2013.

[25] M. Hartmann, H. Ertl, and J. Kolar, "Current control of three-phase rectifier systems using three independent current controllers," IEEE Trans. Power Electron., vol. 28, no. 8, pp. 3988-4000, Aug 2013.

[26] C. Qiao and K. Smedley, "A general three-phase pfc controller for rectifiers with a parallel-connected dual boost topology," IEEE Trans. Power Electron., vol. 17, no. 6, pp. 925-934, Nov 2002.

[27] S. Mariethoz and M. Morari, "Explicit model-predictive control of a pwm inverter with an LCL filter," IEEE Trans. Ind. Electron., vol. 56, no. 2, pp. 389-399, Feb 2009.

[28] N. Youssef, K. Al-Haddad, and H.-Y. Kanaan, "Sensorless nonlinear control of a three-phase/ switch/ level vienna rectifier based on a numerical reconstruction of dc and ac voltages," in Industry Applications Society Annual Meeting, 2008. IAS '08. IEEE, Oct 2008, pp. 1-7.

[29] A. Isidori, Nonlinear Control Systems. New York: Springer Verlag, 1995.

[30] M. Eissa, S. Leeb, G. C. Verghese, and A. Stankovic, "Fast controller for a unity-power-factor pwm rectifier," IEEE Trans. Power Electron., vol. 11, no. 1, pp. 1-6, Jan 1996.

[31] O. Lopez, L. Garcia De Vicuna, M. Castilla, J. Matas, and M. Lopez, "Sliding-mode-control design of a high-power-factor buck-boost rectifier," IEEE Trans. Ind. Electron., vol. 46, no. 3, pp. 604-612, Jun 1999.

[32] E. Figueres, J.-M. Benavent, G. Garcera, and M. Pascual, "Robust control of power-factor-correction rectifiers with fast dynamic response," IEEE Trans. Ind. Electron., vol. 52, no. 1, pp. 66-76, Feb 2005.

[33] E. Figueres, J. Benavent, G. Garcera, and M. Pascual, "A control circuit with load-current injection for single-phase power-factor-correction rectifiers," IEEE Trans. Ind. Electron., vol. 54, no. 3, pp. 1272-1281, June 2007.

[34] P. Rodriguez, A. Luna, I. Candela, R. Mujal, R. Teodorescu, and F. Blaabjerg, "Multiresonant frequency-locked loop for grid synchronization of power converters under distorted grid conditions," IEEE Trans. Power Electron., vol. 58, no. 1, pp. 127-138, Jan 2011.

[35] J. Matas, M. Castilla, J. Miret, L. Garcia de Vicuna, and R. Guzman, "An adaptive prefiltering method to improve the speed/accuracy tradeoff of voltage sequence detection methods under adverse grid conditions," IEEE Trans. Power Electron., vol. 61, no. 5, pp. 2139-2151, May 2014.

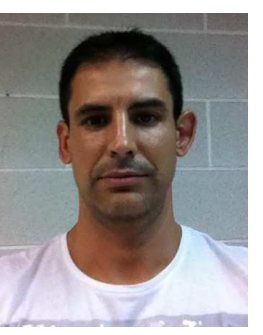

Ramon Guzman received the B.S. and M.S. degrees in telecommunications engineering from the Technical University of Catalonia, Barcelona, Spain, in 1999 and 2004, respectively. He is currently working toward the Ph.D. degree in the Power and Control Electronics Systems Group. Since 2001, he has been an Associate Professor with the Department of Communications and Signal Theory, Technical University of Catalonia, Barcelona, Spain. His current research interests are in the area of nonlinear and adaptive control for three-phase power converters.

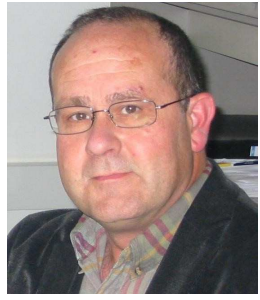

Luis Garcia de Vicuña received the Ingeniero de Telecomunicacin and Dr.Ing. degrees from the Technical University of Catalonia, Barcelona, Spain, in 1980 and 1990, respectively, and the Dr.Sci. degree from the Universit Paul Sabatier, Toulouse, France, in 1992. From 1980 to 1982, he was an Engineer with Control Applications Company. He is currently a Full Professor in the Department of Electronic Engineering, Technical University of Catalonia, where he teaches courses on power electronics. His research interests include power electronics modeling, simulation and control, active power filtering, and high-power-factor ac/dc conversion. 


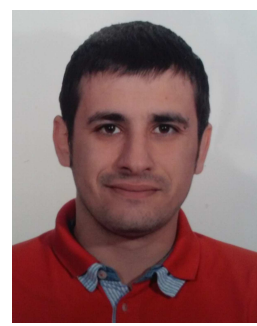

Javier Morales received the B.S. degree in electronics engineering and the M.S. degree in automation and industrial electronics from the Technical University of Catalonia, Barcelona, Spain, in 2012 and 2014, respectively. Currently, he is working towards the Ph.D. degree in electronic engineering at the Technical University of Catalonia. His research interests include automatic control and power electronics.

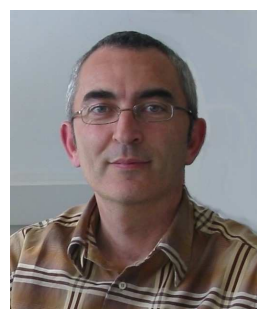

Miguel Castilla received the B.S., M.S. and Ph.D. degrees in telecommunication engineering from the Technical University of Catalonia, Barcelona, Spain, in 1988, 1995, and 1998, respectively. Since 2002, he has been an Associate Professor in the Department of Electronic Engineering, Technical University of Catalonia, where he teaches courses on analog circuits and power electronics. His research interests are in the areas of power electronics, nonlinear control, and renewable energy systems.

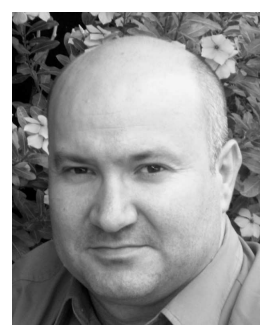

Jose Matas received the B.S., M.S., and Ph.D. degrees in telecommunications engineering from the Technical University of Catalonia, Barcelona, Spain, in 1988, 1996, and 2003, respectively. From 1988 to 1990, he was an Engineer of a consumer electronics company. Since 1990, he has been an Associate Professor in the Department of Electronic Engineering, Technical University of Catalonia, Vilanova i la Geltr, Spain. His research interests include powerfactor-correction circuits, active power filters, uninterruptible power systems, distributed power systems, and nonlinear control. 